\title{
A suitable case for education
}

WE ARE back in the what's-wrong-with-British-industry business again. After a lull of every bit of twelve months during which there has not been a single weighty document for us to consider in all its worthy detail, the Department of Industry has, with some connivance from the Department of Education and Science, put out a discussion paper, Industry, education and management (free from the Department of Industry), which is aimed to "prompt discussion and, more important, action" on the quality of industrial management. The paper fully acknowledges that the poor productivity showing of British industry is by no means exclusively the result of bad management, but tries at least to isolate just a limited number of aspects of the problem-those concerned with technological management by graduates in Britain's manufacturing industries.

If the paper is familiar stuff in many ways, being (so it seems) a distillation of generally expressed views and well-known pieces of information rather than an expression of radically new thoughts, it still serves a useful purpose of confronting the nation yet again with the woeful way in which it doesn't care about engineers and engineering, somehow regarding the creation of wealth as bing a relatively inferior occupation, to be avoided if anything else (preferably involving only paperwork) can be found. The statistics tell the story starkly. As recently as $1969,40 \%$ of graduates entering home employment (excluding the medical sciences) went into manufacturing industries. Now the figure hovers around $25 \%$. At the same time growth in the number of first-degree graduates in science and engineering all but stopped after 1968. Furthermore, tables of after-tax salaries adjusted, as well as can be, for the cost of living in different countries show that top executives on the manufacturing and engineering side are consistently worse paid in the UK than in any other European country. Managerial salaries in industry have lagged very seriously behind inflation and as a result of that and very heavy taxation the salary differential between top executives and average weekly- wage earners is much lower in the UK than anywhere else in Europe save super-egalitarian Sweden.

Nor is there much but gloom in those perceptions of industry which cannot be turned into figures. Television nightly presents the British industrial scene as a battleground between aloof management and irresponsible unions over issues of the most trifling character. Companies are often thought to be run by boards remote from the factory both gographically and in comprehension. Industrial jobs are reckoned to be much more vulnerable than those in the professions, government or academe. Who then is for manufacturing industry; most of all who wants to be on the production sidethe Cinderella of the engineering profession?

All of this has, in one form or another, been talked about ad nauseam in the past few years without as yet any perceptible improvements, and more doses of it are on the way with a British Association report and then the government's own enquiry into the status of engineers. But in the end it is the educational system which must take up the running, if only because it has a flexibility within it that industry does not have. The first step must be to persuade more intelligent young people at least to sample engineering at school and in university. There seems to be some evidence that young people go into engineering on the basis of the impression that local industry makes on them, either through family connections or simply through exposure to nearby activity. It ought then to be the duty of schools to make sure that local industry really makes itself accessible and explains what it is about to schoolchildren.

Schools cannot expect to do this without one or two of their staff having a more than passing acquaintance with industry themselves. And universities should make sure that engineering is better taught, with richer experience. How many students' summers are wasted by selling ice-cream when they should be learning what industry is about by being in it-and how many universities go to much trouble to persuade industry to find summer jobs for their students? 